\author{
Marin Bachvarov \\ Uniwersytet Łódzki \\ Katedra Geografii Miast i Turyzmu \\ 90-142 Łódź \\ ul. Kopcińskiego 31
}

\section{TYPY ŚRODOWISK RECEPCYJNYCH TURYSTYKI - ASPEKT GEOGRAFICZNY}

Zarys treści: Artykuł dotyczy relacji między turystyką a typem środowiska fizycznogeograficznego (krajobrazu recepcyjnego). Wyróżniamy cztery podstawowe recepcyjne środowiska fizyczne (wybrzeża, tereny górskie i podgórskie, równiny i pojezierza, obszary miejskie i podmiejskie). Każde z nich wykazuje znaczną specyfikę tworzenia przestrzeni turystycznej oraz charakterystyczne układy etapów i form rozwoju turystyki. Niezależnie od odmienności poszczególnych środowisk recepcyjnych istnieje uniwersalny trzon relacji środowiska recepcyjnego z turystyka, który w naszym przekonaniu pozwala na uogólnienia teoretyczne, metodyczne i rozwiązania modelowe.

Slowa kluczowe: recepcyjne środowiska fizyczne turystyki, tworzenie przestrzeni turystycznej w środowiskach, dynamika turystyki.

Turystyka jest taka, jakie są potrzeby ludzkie. To one przesądzają o jej genezie i rozwoju. Jednak charakter środowiska geograficznego decyduje o tym, gdzie i jak ona się przejawia, jakie są jej konsekwencje dla otoczenia, a także jaki jest charakter penetracji turystyki w konkretnej przestrzeni geograficznej. Najważniejsze i najlepiej odzwierciedlające istotę turystyki są podzialy według celów podróży, charakteru czynności w miejscu docelowym, efektów społeczno-ekonomicznych turystyki, ram czasowych nałożonych przez typy spędzania wolnego czasu oraz charakteru krajobrazów geograficznych i wplywów turystyki na środowisko recepcyjne. Rozwój turystyki różni się bowiem nie tylko regionalnie, czyli co do obszarów rozwoju, ale również wedle typów środowiska, czyli krajobrazów geograficznych. Inaczej można to określić jako rozwój turystyki na scenach głównych typów krajobrazowych.

\section{TYPES OF TOURISM RECEPTION ENVIRONMENTS - A GEOGRAPHICAL PERSPECTIVE}

Abstract: The article discusses the relation between tourism and types of geographical environment (reception landscapes). There are four basic physical reception environments (coastal areas, mountain and upland areas, plains and lake districts, urban and urban fringe areas). In each of them tourism space is created in a different, distinctive way and characteristic stages and forms of tourism development can be observed. Irrespective of the differences between individual reception environments, there is a universal core relation with tourism, which we believe allows theoretical, methodological generalizations and possible solutions.

Key words: physical reception environments for tourism, creating tourism space in reception environments, varying tourism dynamics.

Tourism follows human needs. They determine its origins and development. However, the character of the geographical environment determines where and how tourism occurs, what its consequences for the surroundings are, and what tourism penetration in a given geographical space will be like. The most important divisions, which reflect the essence of tourism best, are those according: travel aims, destination activities, the socio-economic effects of tourism, time frames imposed by differing ways of spending leisure time, and the character of geographical landscapes and the influence of tourism on the reception environment. The development of tourism varies not only regionally, but also depends on the type of environment, i.e. the geographical landscape. In other 
Problemem naukowym opracowania jest zwrócenie uwagi na doniosłość relacji między typami środowisk recepcyjnych a charakterem i formami, jakie przybiera turystyka.

\section{TURYSTYKA \\ A JEJ FIZYCZNOGEOGRAFICZNE ŚRODOWISKA RECEPCYJNE}

Geneza potrzeb turystycznych ma charakter uniwersalny - nie dotyczy konkretnego terytorium. Realizacja turystyki zaś, zawsze prowadzi do określonej, konkretnej przestrzeni.

Zgodnie $\mathrm{z}$ postawionym tematem, kładziemy nacisk na aspekt dotyczący charakteru turystyki w głównych typach środowisk recepcyjnych (w krajobrazach geograficznych). Przybliżenie podstawowych środowisk fizycznogeograficznych realizacji turystyki pozwala wyodrębnić następujące typy obszarów:

1) w większości zurbanizowane (miejskie i podmiejskie),

2) w większości naturalne (obszary wiejskie), w tym:

- wybrzeża,

- góry i podgórza,

- równinno-nizinne i pojezierne.

W dalszej części pracy - w celu uproszczenia geograficznofizyczne środowiska recepcyjne turystyki będziemy określać „cztery środowiska”.

Należy zaznaczyć, że wymienione środowiska można dekomponować na subśrodowiska, odznaczające się zasadniczymi odmiennościami co do relacji turystyki z otoczeniem. Na przykład odnotowuje się znaczące różnice między terenami wielkomiejskimi, gdzie dominują formy intensywne i sztuczne (antropogeniczne) turystyki, a terenami podmiejskimi, na których turystyka jest oparta przeważnie na fizycznych walorach i sąsiedztwie z popytem ludności pobliskiego miasta.

Nie mając możliwości wejścia w szczegóły W niniejszym opracowaniu pragniemy tylko podkreślić istotne różnice co do form szeroko rozumianej turystyki - proporcje między formami turystyki i zagospodarowaniem. Na przykład we wszystkich środowiskach dużą rolę odgrywa ruch krajoznawczy, jednak dominuje on w środowisku zurbanizowanym. Podobnie jest w przypadku „turystyki po zakupy".

Ruch turystyczny oczywiście nie zamyka się w określonym środowisku, bowiem zachowania words, tourism develops differently in different landscape types.

The aim of the article is to draw the reader's attention to the significance of the relation between types of reception environments and the character and forms of tourism.

\section{TOURISM AND ITS GEOGRAPHICAL RECEPTION ENVIRONMIENTS}

The origins of tourist needs are universal they do not concern any particular landscape. Practical tourism always leads to a given, concrete space.

With reference to the title, we focus on the character of tourism in the main types of reception environments (geographical landscapes). A closer look at the basic tourist geographical environments allows us to identify the following types of areas:

1) mostly urbanized (urban and urban fringe),

2) mostly natural (rural areas), including:

- coastal areas,

- mountains and uplands,

- plains, lowlands and lake districts.

The geographical reception environments of tourism will be referred to for convenience as the 'four environments'.

It should be pointed out that the environments listed above may be divided into sub-environments, displaying considerable differences as regards the relation between tourism and the surrounding area. For instance, there are significant differences between metropolitan areas with predominating intensive and anthropogenic forms of tourism, and urban fringe areas where tourism is usually based on physical assets and demand from the inhabitants of the nearby city.

Being unable here to go into details, we would only like to point to important differences among forms of tourism and the relation between them and their surroundings. For instance, in all environments tourism is of great importance, but it dominates the urbanized environment, for instance shopping tourism.

Tourism is certainly not limited to a given environment, because tourist 
turystyczne obejmują też podróżowanie przez obszary tranzytowe. Ogromna część turystów bierze przecież udzial w krótszych czy dłuższych wycieczkach krajoznawczych, pielgrzymkowych, po zakupy, w poszukiwaniu rozrywki itd. Często środowisko (krajobraz) stacjonowania podczas urlopu jest bazą wypadową wycieczek do innego środowiska.

\section{ROZWÓJ TURYSTYKI W RÓŻNYCH ŚRODOWISKACH GEOGRAFICZNYCH W ŚWIETLE LITERATURY I DOŚWIADCZEŃ ŚRODKOWOEUROPEJSKICH}

Omawiany temat był przedmiotem badań w równinno-nizinnej Polsce Środkowej, ze szczególnym uwzględnieniem obszaru aglomeracji i strefy podmiejskiej Łodzi przez LISZEWSKIEGO (1987). W nawiązaniu do wcześniejszych publikacji ogólnych (HAEGERSTRAND 1963, ŁOBODA 1993), a przede wszystkim dotyczących turystyki (MIosSEC 1976, BUTLER 1980, model lokalizacji turystyki Hotellinga za GOODALLEM 1997 - s. 214, GORMSEN 1981, 1997, OPPERMANN 1993, STACHOWSKI 1993, DZIEGIEĆ 1995, MATCZAK 1986, 1995, 2004, KOWALCZYK 2002, KACZMAREK i in. 2005) i filozofii rozwoju zrównoważonego, LISZEWSKI $(1988,1989,1990,1991,1995)$ wylansował koncepcję rozwoju turystyki w przestrzeni i ,produkowania” (przez człowieka, przez potrzeby ludzkie) specyficznej podprzestrzeni turystycznej. Etapy jej kreowania i realizacji obejmują eksplorację, penetrację, kolonizację, asymilację i urbanizację. Wraz z nasileniem się tych zjawisk środowisko staje się coraz bardziej sztuczne, zmienione pod wplywem turystyki. Niektóre $z$ tych zmian mają charakter utylitarny i są wynikiem wymogów świadczenia różnorodnych usług przyjezdnym, inne zaś prowadzą do „turystyfikacji” i obniżają jakość doznań rekreacyjno-turystycznych. Koncepcja S. Liszewskiego została zweryfikowana w wielu regionach Polski, a także na niektórych obszarach środkowoeuropejskich. Na przykład doświadczenia bułgarskie (BACHVAROV 1997) potwierdzają bliskość tendencji W tworzeniu przestrzeni turystycznej, niezależnie od dużej odmienności przyrodniczej i kulturowej.

Otwarte pozostaje pytanie, w jakim stopniu procesy tworzenia przestrzeni turystycznej są uniwersalne i pozwalają na modelowe rozwiąza- behaviour also takes place while travelling through transit areas. Large numbers of tourists take part in shorter or longer tourist trips, pilgrimages, shopping or entertainment-oriented trips, etc. The environment (landscape) in which a tourist stays during a holiday is often the starting point for trips to other environments.

\section{THE DEVELOPMENT OF TOURISM IN ITS FOUR BASIC NATURAL ENVIRONMENTS THROUGH THE LITERATURE AND CENTRAL EUROPEAN EXPERIENCE}

The issue discussed here has been the object of research carried out in the plains and lowlands of Central Poland, especially in the conurbation and urban fringe zone of Łódź, by LiszewSKI (1987) with reference to earlier publications (HAEGERSTRAND 1963, ŁOBODA 1993), and above all those referring to tourism (MIOssec 1976, BUTLER 1989, Hotelling's model of tourist location: after GOODALL 1997 - p. 214, GORMSEN 1981, 1997, OPPERMANN 1993, StachowsKi 1993, DZIEGIEĆ 1995, MATCZAK 1986, 1995, 2004, KOWALCZYK 2002, KACZMAREK et al. 2005), as well as the philosophy of sustainable development. LISZEWSKI (1988, 1989, 1990, 1991, 1995) launched the concept of tourism development in space and of a specific tourism sub-space. The stages in creating this space include exploration, penetration, colonization, assimilation and urbanization. Along with the growing intensity of these phenomena the environment becomes more and more artificial and altered by tourism. Some of these changes are utilitarian and result from the necessity to provide visitors with a variety of services, while others lead to 'touristification' and decrease the quality of tourist and recreational experience. Liszewski's concept has been verified in many regions of Poland, as well as in some central European areas. The Bulgarian experience $\left(\mathrm{BACH}^{-}\right.$ VAROV 1997) confirms the mechanism of the creation of tourism space, irrespective of considerable natural and cultural differences. 
nia, czy może każde z czterech środowisk recepcyjnych jest tak specyficzne, że stworzenie ogólnej teorii jest watpliwe. Autor niniejszego opracowania skłania się ku pierwszej opinii, którą jednak należy poprzeć dalszymi badaniami szczegółowymi.

$\mathrm{Na}$ terenach równinnych i podmiejskich układ przestrzeni turystycznych ma charakter pasmowo-areałowy (MATCZAK 1986, 1995, DZIEGIEĆ 1995, WILUŚ 1997, WOJCIECHOWSKA 1998, WŁODARCZYK 1999, SZKUP 2003 i in. opracowania publikowane). Naszym zdaniem należy tę koncepcję głębiej skonfrontować w środowiskach wybrzeży oraz gór i podgórzy, bowiem tam tworzenie przestrzeni turystycznej występuje w sposób nieciągly, $\mathrm{z}$ przewagą różnych tendencji przestrzennych (np. konfiguracji liniowo-węzłowej).

Analiza rozwoju turystyki w poszczególnych typach środowisk pozwala na określenie różnych wiodących cech lub wskazanie ich braku. Jest to zilustrowane na poziomie ogólnym, jakościowym, w poniższym zestawieniu (tab. I). Należy zwrócić uwagę na nieproporcjonalnie większą rolę różnych etapów tworzenia podprzestrzeni turystycznej np. penetracji w górach, kolonizacji na wybrzeżach czy urbanizacji turystycznej w miastach i terenach podmiejskich.

Trzeba podkreślić, że środowiska recepcyjne wzajemnie się przenikaja, nie ma między nimi ostrej granicy. Szczególną pozycję zajmują kurorty lecznicze, które są obecne we wszystkich środowiskach, jednak ze względu na tektonikę i, w związku z tym, występowanie obfitych wód termalnych, są typowe dla środowiska gór i podgórzy.

Jak wynika z tab. I, rozwój zrównoważony turystyki najkorzystniej wypada w środowisku wiejskim (równiny i pojezierza). Duże efekty wypoczynkowo-rekreacyjne dają kombinacje pobytów na wsi również na terenach górskich i nadmorskich.

$\mathrm{Na}$ obszarach, gdzie turystyka stala się gałęzią wiodąca, czasem monokulturowa, i wskutek tego doszło do glębokich zmian, mamy do czynienia ze zjawiskami, które w literaturze francuskojęzycznej określane są terminem ,turystyfikacja” (DEWAILLY, FLAMENT 1996). Sa to zaawansowane $i$ trudno odwracalne konsekwencje turyzmu dla całego życia społeczno-ekonomicznego obszarów docelowych lub tranzytowych. Jest to pojęcie o negatywnej konotacji. Turystyfikacja jest obserwowana $w$ masowo uczęszczanych przez turystów uzdrowiskach nadmorskich, górskich
It is an open question whether the processes creating tourism space are universal and allow possible solutions, or perhaps each of the four reception environments is so distinct that the purpose of formulating a general theory should be doubted. The author opts for the first which, nevertheless, should be supported by further detailed study.

In lowland and urban fringe areas individual tourism spaces are concentric (MATCZAK 1986, DZIEGIEĆ 1995, WILUŚ 1997, WOJCIECHOWSKA 1998, WLODARCZYK 1999, SzKuP 2003, and other publications).

In our opinion, this concept should be further considered in the environments of coastal areas, as well as mountains and uplands, because there the creation of tourism space there is not continuous but dominated by different spatial trends (e.g. a linear-nodal configuration).

An analysis of tourism development in individual environments allows us to define various primary features or indicate their absence. It is illustrated in a general, qualitative way in the table below (table I). It should be noticed that the role of different stages in the creation of a tourism space differs - e.g. the role of penetration in the mountains, colonization on the coast or urbanization in cities and urban fringe areas.

It must be stressed that reception areas penetrate into one another; there is no clear boundary between them. A part-icular case is that of spa resorts which can be found in all environments, but due to tectonic conditions and the abundance of thermal waters, they are typical of mountains and uplands.

As can be seen from the table, sustainable tourism development is best in the rural environment (lowlands and lake districts). Considerable recreational effects are also achieved while staying in the country in the mountains or at the seaside.

In the areas where tourism has become a predominant, often single force caus-ing serious changes, we observe the phenomenon of touristification (DEWAILLY \& FLAMENT 1996). This is the advanced and virtually irreversible consequence of tourism for the whole socio-economic life of destination or transit areas. It is a negative phenomenon. Touristification is observed in popular 
$T a$ b $\theta$ I a I. Cechy turystyki w różnych środowiskach geograficznych

\begin{tabular}{|c|c|c|c|c|}
\hline $\begin{array}{l}\text { Cechy/aspekty } \\
\text { furystyki }\end{array}$ & $\begin{array}{c}\text { Wybrze- } \\
\text { za }\end{array}$ & $\begin{array}{c}\text { Góry } \\
\text { ipodgórza }\end{array}$ & $\begin{array}{l}\text { Równi- } \\
\text { ny/ po- } \\
\text { jezie- } \\
\text { rza }\end{array}$ & $\begin{array}{c}\text { Miasta } \\
\text { i obszary } \\
\text { podmiejskie }\end{array}$ \\
\hline $\begin{array}{l}\text { Ruch } \\
\text { furystyczny }\end{array}$ & $\begin{array}{l}\text { ogromny, } \\
\text { skoncen- } \\
\text { trowany }\end{array}$ & $\begin{array}{l}\text { duży, skon- } \\
\text { centrowa- } \\
\text { ny, rozpro- } \\
\text { szony }\end{array}$ & $\begin{array}{l}\text { mahyl } \\
\text { średni, } \\
\text { rozpro- } \\
\text { szony }\end{array}$ & $\begin{array}{c}\text { duży, } \\
\text { skoncentrowany }\end{array}$ \\
\hline $\begin{array}{l}\text { Zagospodaro- } \\
\text { wanie }\end{array}$ & $\begin{array}{l}\text { ogromne, } \\
\text { skoncen- } \\
\text { trowane, } \\
\text { urozma- } \\
\text { icone }\end{array}$ & $\begin{array}{l}\text { duże, } \\
\text { skoncen- } \\
\text { trowane, } \\
\text { lekkie }\end{array}$ & mate & $\begin{array}{l}\text { duże, skoncentro- } \\
\text { wane w sródmie- } \\
\text { sciu, małe na } \\
\text { peryferiach }\end{array}$ \\
\hline $\begin{array}{l}\text { Kontynualność } \\
\text { przestrzenna }\end{array}$ & duża & mała & duża & mała/średnia \\
\hline Zarzagdzanie & $\begin{array}{l}\text { wielko- } \\
\text { skalowe, } \\
\text { familine }\end{array}$ & regionalne & lokalne & $\begin{array}{l}\text { wielkoskalowe, } \\
\text { lokalne }\end{array}$ \\
\hline Wachlarz ustug & ogromny & duży & średni & ogromny \\
\hline Finansowanie & $\begin{array}{l}\text { krajowe, } \\
\text { ponad- } \\
\text { krajowe }\end{array}$ & $\begin{array}{l}\text { krajowe, } \\
\text { lokalne }\end{array}$ & lokalne & $\begin{array}{c}\text { ponadkrajowe, } \\
\text { krajowe, } \\
\text { regionalne }\end{array}$ \\
\hline $\begin{array}{l}\text { Komercjaliza- } \\
\text { cja }\end{array}$ & duża & $\begin{array}{c}\text { duża, } \\
\text { średnia }\end{array}$ & mała & duża \\
\hline Socjalizacja & mała & $\begin{array}{l}\text { średnia, du- } \\
\text { ża (w uz- } \\
\text { drowiskach) }\end{array}$ & duża & mała \\
\hline $\begin{array}{l}\text { Tendencja linio- } \\
\text { wo-węzłowa }\end{array}$ & duża & duża & mała & średnia/duża \\
\hline $\begin{array}{l}\text { Tendencja wę- } \\
\text { złowa }\end{array}$ & duża & duża & mata & duża \\
\hline $\begin{array}{l}\text { Tendencja area- } \\
\text { towo-pasmowa }\end{array}$ & mała & srednia & duża & mała \\
\hline Rola eksploracji & mała & duża & duża & mała \\
\hline Rola penetracji & mała & duża & duża & duża/mała \\
\hline Rola asymilacji & duża & duża & średnia & średnia \\
\hline Rola kolonizacji & duża & średnia & średnia & średnia/duża \\
\hline Rola urbanizacji & duża & średnia & mała & duża \\
\hline $\begin{array}{l}\text { Udział sektora } \\
\text { formalnego }\end{array}$ & duży & duży & mały & duży/średni \\
\hline $\begin{array}{l}\text { Udział sektora } \\
\text { paraturystycz- } \\
\text { nego }\end{array}$ & duży & $\begin{array}{l}\text { duży } \\
\text { Iśredni }\end{array}$ & duży & duży \\
\hline $\begin{array}{l}\text { Ingerencja } \\
\text { w środowisku } \\
\text { fizycznym }\end{array}$ & duża & średnia & mała & duża/mała \\
\hline $\begin{array}{l}\text { Ingerencja } \\
\text { w środowisku } \\
\text { spoteczno- } \\
\text {-kulturowym }\end{array}$ & duża & duża & $\begin{array}{l}\text { mała/ } \\
\text { śednia }\end{array}$ & duża/średnia \\
\hline $\begin{array}{l}\text { Dynamika } \\
\text { zmian }\end{array}$ & duża & duża & $\begin{array}{l}\text { małal } \\
\text { średnia }\end{array}$ & średnia/duża \\
\hline $\begin{array}{l}\text { Rozwój } \\
\text { zrównoważony }\end{array}$ & $\begin{array}{l}\text { zagro- } \\
\text { żony }\end{array}$ & $\begin{array}{c}\text { lokalnie } \\
\text { zagrożony }\end{array}$ & $\begin{array}{l}\text { korzy- } \\
\text { stny }\end{array}$ & $\begin{array}{l}\text { w miastach zagro- } \\
\text { żony, w strefach } \\
\text { podmiejskich } \\
\text { korzystny }\end{array}$ \\
\hline
\end{tabular}

Żródło: Opracowanie autora.

i leczniczych oraz w niektórych miastach kultury (BORG, van den 1994). Mówi się też o krajobrazach przekształconych przez turystykę (ang. vacationscapes) - to określenie nie wartościuje negatywnie, bowiem jest postrzegane jako estetyzacja krajobrazu pod kątem podkreślenia jego atrakcyjności.
$T a b|e|$. Features of tourism in the four reception environments

\begin{tabular}{|c|c|c|c|c|}
\hline $\begin{array}{l}\text { Tourism } \\
\text { features }\end{array}$ & $\begin{array}{l}\text { Coastal } \\
\text { areas }\end{array}$ & $\begin{array}{l}\text { Mountains } \\
\text { and uplands }\end{array}$ & $\begin{array}{c}\text { Lowlands } \\
\text { /lake } \\
\text { districts }\end{array}$ & $\begin{array}{l}\text { Cities and } \\
\text { urban fringe } \\
\text { areas }\end{array}$ \\
\hline Tourist activity & $\begin{array}{c}\text { huge, } \\
\text { con- } \\
\text { centrated }\end{array}$ & $\begin{array}{c}\text { considerable, } \\
\text { concentrated, } \\
\text { dispersed }\end{array}$ & $\begin{array}{c}\text { small/me } \\
\text { dium, } \\
\text { dispersed }\end{array}$ & $\begin{array}{l}\text { considerable, } \\
\text { concentrated }\end{array}$ \\
\hline Infrastructure & $\begin{array}{c}\text { huge, } \\
\text { con- } \\
\text { centrated } \\
\text { varied }\end{array}$ & $\begin{array}{c}\text { considerable, } \\
\text { concentrated, } \\
\text { light }\end{array}$ & light & $\begin{array}{l}\text { considerable, } \\
\text { concentrated in } \\
\text { the city centre, } \\
\text { light in the } \\
\text { peripheries }\end{array}$ \\
\hline $\begin{array}{l}\text { Spatial } \\
\text { continuity }\end{array}$ & $\begin{array}{c}\text { consider- } \\
\text { able }\end{array}$ & low & $\begin{array}{c}\text { consider- } \\
\text { able }\end{array}$ & small/medium \\
\hline Management & $\begin{array}{c}\text { large } \\
\text { scale, } \\
\text { familial }\end{array}$ & regional & local & $\begin{array}{c}\text { large scale, } \\
\text { local }\end{array}$ \\
\hline Service range & huge & considerable & medium & huge \\
\hline Financing & $\begin{array}{l}\text { national, } \\
\text { foreign }\end{array}$ & national, local & local & $\begin{array}{l}\text { foreign, } \\
\text { national, } \\
\text { regional }\end{array}$ \\
\hline $\begin{array}{l}\text { Commerciali- } \\
\text { sation }\end{array}$ & $\begin{array}{c}\text { consider- } \\
\text { able }\end{array}$ & $\begin{array}{c}\text { considerable, } \\
\text { medium }\end{array}$ & low & considerable \\
\hline $\begin{array}{l}\text { Social } \\
\text { ownership }\end{array}$ & small & $\begin{array}{c}\text { medium, } \\
\text { considerable } \\
\text { (in spas) }\end{array}$ & $\begin{array}{c}\text { consider- } \\
\text { able }\end{array}$ & low \\
\hline $\begin{array}{l}\text { Linear-nodal } \\
\text { tendency }\end{array}$ & $\begin{array}{c}\text { consider- } \\
\text { able }\end{array}$ & considerable & low & $\begin{array}{c}\text { medium/ } \\
\text { considerable }\end{array}$ \\
\hline $\begin{array}{l}\text { Nodal } \\
\text { tendency }\end{array}$ & $\begin{array}{c}\text { consider- } \\
\text { able }\end{array}$ & considerable & low & considerable \\
\hline $\begin{array}{l}\text { Concentric } \\
\text { tendency }\end{array}$ & low & medium & $\begin{array}{c}\text { consider- } \\
\text { able }\end{array}$ & low \\
\hline $\begin{array}{l}\text { Role of } \\
\text { exploration }\end{array}$ & low & considerable & $\begin{array}{l}\text { consider- } \\
\text { able }\end{array}$ & low \\
\hline $\begin{array}{l}\text { Role of } \\
\text { penetration }\end{array}$ & low & considerable & $\begin{array}{c}\text { consider- } \\
\text { able }\end{array}$ & low \\
\hline $\begin{array}{l}\text { Role of } \\
\text { assimilation }\end{array}$ & $\begin{array}{c}\text { consider- } \\
\text { able }\end{array}$ & considerable & medium & medium \\
\hline $\begin{array}{l}\text { Role of } \\
\text { colonization }\end{array}$ & $\begin{array}{c}\text { consider- } \\
\text { able }\end{array}$ & medium & medium & $\begin{array}{c}\text { medium/ } \\
\text { considerable }\end{array}$ \\
\hline $\begin{array}{l}\text { Role of } \\
\text { urbanization }\end{array}$ & $\begin{array}{c}\text { consider- } \\
\text { able }\end{array}$ & medium & low & considerable \\
\hline $\begin{array}{l}\text { Percentage of } \\
\text { formal tourist } \\
\text { sector }\end{array}$ & $\begin{array}{c}\text { consider- } \\
\text { able }\end{array}$ & considerable & low & $\begin{array}{l}\text { considerable } \\
\text { Imedium }\end{array}$ \\
\hline $\begin{array}{l}\text { Percentage of } \\
\text { paratourist } \\
\text { sector }\end{array}$ & $\begin{array}{c}\text { consider- } \\
\text { able }\end{array}$ & $\begin{array}{l}\text { considerable/ } \\
\text { medium }\end{array}$ & $\begin{array}{c}\text { consider- } \\
\text { able }\end{array}$ & considerable \\
\hline $\begin{array}{l}\text { Interference } \\
\text { with the } \\
\text { physical } \\
\text { environment }\end{array}$ & $\begin{array}{l}\text { consider- } \\
\text { able }\end{array}$ & medium & low & $\begin{array}{c}\text { considerable/ } \\
\text { low }\end{array}$ \\
\hline $\begin{array}{l}\text { Interference } \\
\text { with the socio- } \\
\text { cultural } \\
\text { environment }\end{array}$ & $\begin{array}{c}\text { consider- } \\
\text { able }\end{array}$ & considerable & $\begin{array}{c}\text { low } \\
\text { Imedium }\end{array}$ & $\begin{array}{l}\text { considerable } \\
\text { /medium }\end{array}$ \\
\hline Rate of change & $\begin{array}{c}\text { consider- } \\
\text { able }\end{array}$ & considerable & $\begin{array}{c}\text { low } \\
\text { Imedium }\end{array}$ & $\begin{array}{c}\text { medium/ } \\
\text { considerable }\end{array}$ \\
\hline $\begin{array}{l}\text { Sustainable } \\
\text { development }\end{array}$ & at risk & locally at risk & fair & $\begin{array}{l}\text { at risk in cities, } \\
\text { fair in urban } \\
\text { tringe zones }\end{array}$ \\
\hline
\end{tabular}

seaside and mountain spas and in some cities of culture (BoRG, van den 1994). We can also talk about vacationscapes; this notion does not bring negative connotations because it is perceived as the aesthetization of land-scape, focusing on its attractiveness. 


\section{TURYSTYKA W CZTERECH PODSTAWOWYCH TYPACH ŚRODOWISK RECEPCYJNYCH}

\section{TOURISM IN THE FOUR BASIC TYPES OF RECEPTION ENVIRONMENT}

1. Środowisko wybrzeży. Jest to typ środowiska, które charakteryzuje najbardziej masowa turystyka w skali świata - popularnie nazywana „turystyką trzech S". To turystyka mocno ingerująca w środowisko fizycznogeograficzne. Oprócz tej prostej i, dodajmy, najczęściej biernej turystyki z tym środowiskiem są kojarzone sporty wodne. Dlatego w kurortach amerykańskich i śródziemnomorskich główne urządzenia turystyki aktywnej nie są zlokalizowane na plażach, lecz zwykle funkcjonują wokół tzw. „mariny” - obszaru przystani jachtów i urządzeń żeglugi dla przyjemności, z przylegającymi terenami handlowymi i rozrywkowymi.

Dużym ogranicznikiem turystyki w tym środowisku jest sezonowość jej uprawiania na otwartych terenach. Im większe jest oddalenie od równika, tym większa jest sezonowość. W chłodniejszej części roku temperatura wody i powietrza nie pozwala na plażowanie i kapanie się w otwartych akwenach. Jednak sezonowość jest powodowana nie tylko warunkami klimatycznymi, ale także uwarunkowaniami spoleczno-kulturowymi (np. ograniczony czas urlopów i wakacji, tradycyjne uprawianie tych dyscyplin w lecie itd.).

Wlaściwie ruch turystyki ekologicznej i alternatywnej (inicjatywy takie, jak „Blękitna Flaga” i wiele innych) powstaly jako reakcja na turystykę brutalnie kolidującą $\mathrm{z}$ otoczeniem. W ostatnich latach wysilki wdrożenia zasad ekorozwoju i rozwoju zrównoważonego w destynacjach turystycznych dały pewne pozytywne efekty: bardziej czyste akweny i powietrze, lepsza jakość usług, poprawa warunków higieny, pomocy medycznej i ratownictwa, więcej usług i urządzeń sportowych.

2. Środowisko górskie i podgórskie. Tu panują najbardziej kompleksowe warunki dla turystyki (duże zróżnicowanie walorów przyrodniczych, ich wysoka wartość lecznicza i profilaktyczna). Istnieje znaczne zróżnicowanie potencjału rekreacyjno-turystycznego nie tylko pomiędzy górami wysokimi, średnimi i niskimi, lecz i między poszczególnymi obszarami górskimi, które cechuje indywidualność (każda góra odznacza się niepowtarzalnościa).

W górach niskich są dobre warunki do uprawiania masowej rekreacji - czyste powietrze, las i sze-
1. The coastal environment. This is a type of environment which is characterized by the mass tourism, popularly known as the 'three S's'. It strongly interferes with the geographical environment. Apart from this simple and usually passive form of tourism, this environment is associated with water sports. That is why in American and Mediterranean resorts the main active tourist facilities are located not on beaches but around marinas -together with adjacent shopping and entertainment facilities.

Serious limitations imposed on tourism in this environment result from its seasonality - the further from the equator, the higher the seasonality. In the cooler part of the year the temperatures of the water and air are too low to sunbathe or swim in open water. However, seasonality is caused not only by the climate, but also by the socio-cultural conditions (e.g. limited holiday season, certain sports are summer only, etc.)

As a matter of fact, ecological and alternative tourism (initiatives such as 'Blue Wave' and many others) emerged as a reaction to tourism brutally colliding with its surroundings. In recent years efforts to introduce the principles of ecodevelopment and sustainable development at tourist destinations have brought certain positive results: cleaner water and air, higher quality of service, improved hygiene and medical aid, more services and sports facilities.

\section{Mountain and upland environment.}

This offers the most complex conditions for tourism (a large variety of natural assets, their high therapeutic and prophylactic value). The recreational and tourist potential in high, medium or lowaltitude mountains varies widely, and differences are also easily observable between individual mountain areas which often display strong individuality (each mountain is unique).

Low mountains offer good conditions for mass recreation - clean air, forests and 
rokie polany, latwy dostęp. Są tu szczególnie odpowiednie warunki do wypoczynku dla dzieci (kolonie), osób w tzw. „trzecim wieku”, wypoczynku w domkach wczasowych i kempingowych, do uprawiania turystyki pieszej, do zbioru owoców leśnych, a także do wykonywania innych czynności nie wymagających dużego wysilku fizycznego. Są to również dobre tereny do lokalizacji drugich domów (przykład z Polski - Góry Świętokrzyskie).

W średnich górach glównym terenem rekreacyjnym są kompleksy leśne, sieci schronisk i szlaków wędrówek, ośrodków wczasowych i sportów zimowych, szczyty i miejsca widokowe (przykład w Polsce - Sudety).

W wysokich górach można uprawiać turystykę specjalistyczną (kwalifikowana) i wyczynową. Jest to domena sportów zimowych i alpinizmu. W dolinach wysokogórskich powstają duże centra sportów zimowych i sieci wyciągów, tras narciarskich, skoczni i innych urządzeń. Warunkiem stworzenia kurortu narciarskiego jest, zgodnie z normą francuska, obecność pokrywy śnieżnej 0 grubości powyżej $10 \mathrm{~cm}$ co najmniej przez 120 dni, w Polsce - 100 dni. W górach wysokich zimą występuja niskie temperatury, zawieje śnieżne, lawiny, silny wiatr $\mathrm{i}$ intensywne promieniowanie ultrafioletowe. W związku tym pobyt w wysokich górach jest związany $\mathrm{z}$ różnymi niebezpieczeństwami, wymaga funkcjonowania ratownictwa górskiego, pierwszej pomocy (np. przy złamaniach lub ochłodzeniu). Pobyty rekreacyjno-turystyczne w wysokich górach implikują wysoki poziom wysportowania, specjalistycznych umiejętności, zdrowia. Dlatego też wysokie góry nie są zalecane dla małych dzieci, dla osób w wieku podeszlym, ludzi o pewnych schorzeniach (np. nadciśnieniowcy). Wraz $\mathrm{z}$ rozpowszechnieniem narciarstwa góry, szczególnie wysokie, stały się główną domeną turystyki zimowej. Wobec tego obecnie na obszarach wysokich gór dominuje sezon zimowy, chociaż lato w górach (przeważnie niższych) również przyciąga milionowe rzesze turystów. Rozwinęła się tutaj turystyka letnia, klimatyczna, lecznicza (np. na leczenie choroby wieku XIX - gruźlicy). Posługując się przykładem z Alp austriackich trzeba przyznać, że latem przyjeżdża tutaj wprawdzie więcej gości, to jednak zima pobyty są znacznie dluższe, w związku z czym odnotowuje się dużo więcej noclegów, a tym samym i zysków.

3. Obszary wiejskie (tereny równinno-nizinne, Wsie, pojezierza, lasy, tereny rolnicze). Turystyka spacious meadows, easy access. There are particularly good conditions for children's holidays, hiking, camping, and for the elderly picking forest fruit and doing other activities which do not require a great physical effort. They are also good areas to locate second homes (e.g. the Swiętokrzyskie Mountains in Poland).

In medium-altitude mountains the main recreational areas are forests, holiday resorts, networks of tourist shelters and hiking trails, winter sports centres, mountain peaks and panoramic sites (e.g. the Sudety Mountains in Poland).

In high mountains specialist tourism such as winter sports and alpinism are possible. In high mountain valleys large winter resorts with ski lifts, ski runs, ski jumps and other facilities are built. A condition to be met when building a ski resort is the presence of a snow layer thicker than $10 \mathrm{~cm}$ for at least 120 days (French standard) or 100 days in Poland. In high mountains in winter there are low temperatures, blizzards, avalanches, strong winds and intensive ultraviolet radiation. As a result, high mountains pose different dangers, and require highly qualified mountain rescue and first aid teams (e.g. for fractures and hypothermia). Tourist and recreational stays in high mountains require fitness, special skills and good health. Therefore these areas are not recommended for young children, the elderly or those suffering from certain illnesses (e.g. high blood pressure). As skiing has increased in popularity, high mountains have become the main domain for winter tourism. At present it is the winter season that dominates, although summer in the mountains (especially in lower ones) also attracts millions of tourists. Summer climatic and therapeutic tourism (e.g. treatment of the $19^{\text {th }} \mathrm{c}$. disease of tuberculosis) greatly developed there. The example of the Austrian Alps shows that in summer there are more visitors, but in winter their stays are much longer, which results in higher profits.

3. Rural areas (plains and lowlands, lake districts, fields). Tourism began in these areas most recently because they cannot compete with the mountains and the coast 
wkroczyła najpóźniej na te tereny, które nie mogą ciągle konkurować $\mathrm{z}$ górami i wybrzeżami morskimi pod względem jakości walorów rekreacyjnych. Jest to środowisko, które oferuje dobre warunki dla turystyki na wsi - turystyki rodzinnej, relaksu, ciepłej i spokojnej atmosfery wypoczynku, w warunkach skromnych, nie pretensjonalnych, ale w bliskim kontakcie z przyroda, kulturą ludową miejscową kuchnią i innymi atrakcjami pobytu na wsi. W Polsce mylnie przyjęto dla turystyki w tym środowisku termin ,agroturystyka” (DRZEWIECKI 1992, SZWICHTENBERG 1998), bowiem tam, gdzie zrodziło się to pojęcie w latach 50. XX w. (Francja i Włochy), agroturystyka oznaczala uczestniczenie turysty w pracy rolnika $w$ celach rekreacyjnych lub poznawczych (np. w winobraniu, produkcji sera, garncarstwie itd.).

4. Obszary zurbanizowane (głównie metropolie). Jest to środowisko w wysokim stopniu sztuczne, „wyprodukowane" czy zmienione przez czlowieka. Walory rekreacyjne są $\mathrm{w}$ zwiazku $\mathrm{z}$ tym niskie (z wyjątkiem miast leczniczych lub takich, które znajdują się bezpośrednio obok atrakcyjnych walorów przyrodniczych). Środowisko miejskie jest natomiast szczególnie bogate $\mathrm{w}$ atrakcje antropogeniczne - architektura, muzea, zabytki, obiekty kulturowe, wystawy, targi. W miastach maja miejsce najważniejsze wydarzenia polityczne i gospodarczo-biznesowe. Tam też odbywają się największe imprezy rozrywkowe. Miasta są również magnesem dla turystyki sentymentalnej, nostalgicznej, literackiej, poszukiwania „korzeni” itd. Ta turystyka skoncentrowana jest głównie w śródmieściach (GETZ 1993, ASHworTH 1994), na tzw. starówkach i w CBD (Śródmiejska Dzielnica Biznesowa). Poza tym miasta, a raczej pewne ich dzielnice i miejsca (zabytki, świątynie, place, ulice), odznaczają się specyficzną atmosferą (duch miejsca), która sama w sobie jest atrakcją dla wielu osób. Szczególnie ważnym celem ruchu turystycznego są miasta o długiej historii, miasta stołeczne, tzw. miasta „magiczne”, takie jak Paryż, Rzym, Jerozolima, Manhattan, St. Petersburg, Wiedeń, Praga, Kraków, Istambul, San Francisco, Hongkong itd. Z miastami dużymi i mniejszymi miastami kultury (Wenecja, Florencja, Salzburg, Brugia, Oxford, Toledo, Kazimierz Dolny, Dubrownik itd.) wiąże się ogromny ruch krajoznawczy (drugi co do wielkości na świecie po turystyce „nad woda”). Podobnie miasta święte dla różnych religii, takie jak Watykan, Lourdes, Santiago di Compostella, Benares, Mekka, Sergiew Posad, kojarzą się z masową turystyką pielgrzymkową. as far as recreational assets are concerned. It is an environment which offers good conditions for rural tourism - family tourism, relaxation, warm and peaceful atmosphere, modest but unpretentious standards, close contact with nature, folklore, local cuisine and other country attractions. In Poland tourism in this environment has been confused with agrotourism (DRZEWIECKI 1992, SZWICHTENBERG 1998), because in France and Italy, where this idea was born in the 1950s, agrotourism meant the tourist's participation in agricultural work for recreational purposes or curiosity (e.g. grape-picking, cheese production, pottery, etc.)

4. Urbanized areas (mainly metropolitan cities). It is a highly artificial environment, to a large extent 'produced' or altered by man. So as a result its recreational assets are of low quality (except health resorts or those near attractive natural assets). The urban environment, on the other hand, is very rich in anthropogenic attractions architecture, museums, historical monuments, cultural sites, exhibitions or fairs. Cities are where the most important political, economic and entertainment events take place. Cities are also a magnet attracting sentimental, nostalgic tourism (search for 'roots'), as well as literary tourism. These types are mainly found in city centres (GETZ 1993, ASHWORTH 1994), in 'old towns' and in the CBD. Besides, cities or rather some of their districts and sites (historical monuments, shrines, squares, streets), have a particular atmosphere (spiritus loci), which for many is an attraction in itself. Particularly important tourism destinations are cities with a long history, capitals, 'magical cities' such as Paris, Rome, Jerusalem, Manhattan, St Petersburg, Vienna, Prague, Krakow, Istanbul, San Francisco, Hong Kong, etc. Largescale tourism (the second largest after coastal tourism) occurs in large cities and in smaller cities or towns of culture (Venice, Florence, Salzburg, Bruges, Oxford, Toledo, Kazimierz, Dubrovnik, etc.). Similarly, holy cities, such as the Vatican, Lourdes, Santiago de Compostela, Benares, Mecca, Sergiew Posad, are associated with pilgrimage tourism. 
Środowiska zurbanizowane obejmują też tereny podmiejskie (turystyka weekendowa mieszkańców miast); często są to obszary nieciekawe przyrodniczo, ale ich walorem jest możliwość szybkiego i regularnego dostępu z miasta, bliskość centrów popytu.

\section{PODSUMOWANIE}

Omawiając problematykę relacji między turystyką a typem środowiska (krajobrazu) recepcyjnego wyróżniono cztery podstawowe recepcyjne środowiska fizycznogeograficzne (wybrzeża, tereny górskie i podgórskie, równiny i pojezierza, obszary miejskie i podmiejskie). Każde $\mathrm{z}$ nich wykazuje znaczną specyfikę tworzenia przestrzeni turystycznej (LISZEWSKI 1995) oraz charakterystyczną sukcesję etapów i form rozwoju turystyki. Jednocześnie zachodzi duże wzajemne przenikanie między środowiskami recepcyjnymi. Podstawowe środowiska recepcyjne można dekomponować dalej na subśrodowiska, szukając ich specyfiki i wspólnych cech, np. na tereny podmiejskie, na góry wysokie, średnie i niskie, na pojezierza, lasy równinne itd. Jest to obiecująca ścieżka badań. Skłaniam się ku opinii, iż niezależnie od odmienności poszczególnych środowisk recepcyjnych istnieje uniwersalny trzon relacji środowiska recepcyjnego z turystyka, który pozwala na uogólnienia teoretyczne, metodyczne i rozwiązania modelowe. Kierunki dalszych badań nad zarysowaną problematyką powinny objąć zagadnienia typu:

- specyfika turystyki w czterech środowiskach i subśrodowiskach;

- specyfika „produkowania” przestrzeni turystycznej w środowiskach i subśrodowiskach;

- relacje między typem środowiska (krajobra-

zu) a regionalizacją turystyczna;

- stopień turystyfikacji i poziom rozwoju zrównoważonego w poszczególnych środowiskach;

- wzajemne przenikanie i efekty synergiczne środowisk recepcyjnych turystyki.
Urbanized environments include urban fringe areas (weekend tourism for city inhabitants); they are areas which are unattractive as regards natural conditions, but their assets include quick and regular access to the city and their short distance from centres of demand.

\section{CONCLUSIONS}

When discussing the relation between tourism and types of reception environment (landscapes), the author has enumerated four basic geographical reception environments (coastal, mountain and upland, plains and lake districts, urban and urban fringe). Each of them displays an individual character leading to the creation of tourism space (LISZEWSKI 1995) and a characteristic succession of stages and forms of tourism development. At the same time, considerable mutual penetration of reception environments can be observed. When looking for their special character and features, the basic reception environments may be divided further into sub-environments, e.g. urban fringe areas, high, medium and low-altitude mountains, lake districts, lowland forests, etc. It is a promising line of study. I tend to believe that irrespective of the differences between individual reception environments, there is a universal core relation between a reception environment and tourism, which allows theoretical and methodological generalizations to be made and possible solutions to be applied. Further research should include the following issues:

- the special character of tourism in the four environments and sub-environments;

- the special character of tourism space production in the environments and subenvironments;

- the extent of touristification and the level of sustainable development in individual environments;

- mutual penetration and synergy effects in the tourism reception environments. 


\section{BIBLIOGRAFIA - BIBLIOGRAPHY}

AsHworTh G., 1994, Heritage. Tourism and Sustainability. Tilburg University Press.

BACHVAROV M., 1997, Recreational and tourist functions of the settlements (bulg.), Yearbook of the Sofia University. Geography, 30.

BorG, van den, I., 1994, Demand for city tourism in Europe, Tourism Management, 1.

BUTLER R. W., 1980, The concept of the tourism area cycle of evolution: implications for management of resources, Canadian Geographer, 24.

DEWAilly J.-M. FlamENT E., 1996, Geographie du tourisme et des loisirs, ed. SEDES, Paris.

DRZEWIECKI M., 1992. Wiejska przestrzeń rekreacyjna, Problemy Turystyki.

DzIEGIEĆ E., 1995, Urbanizacja turystyczna terenów wiejskich w Polsce, Turyzm, 5/1.

GETZ D., 1993, Planning for tourism business districts, Annals of Tourism Research, 20, 4.

GoodAll B., 1997, Dictionary of Human Geography, Penguin Books.

GORMSEN E., 1981, The spatio-temporal development of international tourism: attempt at a centre-periphery model. [w:] La consommation de l'espace par le tourtsme et sa preservation, C. H. E. T., Aix-en-Provence.

GORMSEN E., 1997, The impact of tourism on coastal areas, GeoJournal, 42, 1.

HAEgerstrand T., 1963, Diffusion of Innovation, Lund University Press.

KaczmareK J., Stasiak A., Wlodarczyk B., 2005, Produkt turystyczny. Pomyst, organizacja, zarzadzanie, PWE. Warszawa.

KOWALCZYK A., 2002, Transformacja przestrzeni turystycznej miasta. Problemy lokalizacji usług hotelarskich w Warszawie, [w:] Węcławowicz G. (red.), Warszawa jako przedmiot badań w geografii społecznoekonomicznej, Prace Geograficzne, 184.

Liszewski S., 1987, Geneza 1 rozwój osadnictwa wypoczynkowego w otoczeniu Lodzi, Acta Universitatis Lodziensis. Turyzm, 3.

LISZEWSKI S., 1988, Funkcja osadnictwa nadmorskiego w świetle analizy ruchu turystycznego. Przykład Mierzei Helskiej, Acta Universitatis Lodziensis. Turyzm, 4.

LISZEWSKI S. (red.), 1989, Funkcja turystyczna Augustowa, Instytut Turystyki, Warszawa.
Liszewskı S., 1990, Wpływ turystyki na rozwój miejscowości Polańczyk w Bieszczadach polskich, Acta Universitatis Lodziensis. Turyzm, 6.

LISZEWSKI S., 1991, Spała. Morfologia 1 funkcja miejscowości wypoczynkowej, Turyzm, 1/2.

LISzEWSKI S., 1995, Przestrzeń turystyczna, Turyzm, 5/2.

ŁOBODA J., 1983, Rozwój koncepcji i modeli przestrzenne dyfuzji innowacji. Acta Universitatis Wratislaviensis. Studia Geograficzne, 37.

MATCZAK A., 1986, Budownictwo letniskowe w strefie podmiejskiej Lodzi, Acta Universitatis Lodziensis. Folia Geographica, 14.

MATCZAK A., 1995, Kolonizacja turystyczna obszarów wiejskich w strefie podmiejskiej Łodzi, [w:] Zmiany $w$ przestrzeni geograficznej $w$ warunkach transformacji społeczno-ekonomicznej (na przykładzie obszarów wiejskich). Materiaty XI polsko-czeskiego seminarium geograficznego, Łukęcin. Wydawnictwo Uniwersytetu Warszawskiego, Warszawa.

MATCZAK A. (red.), 2004, Lokalizacja hotell $w$ krajowych metropoliach Europy Srodkowowschodniej, ser. „Szlakami Nauki", 33, Łódzkie Towarzystwo Naukowe, Lódź.

Miossec J. M., 1976, Elements pour une theorie de l'espace touristique, CHET, Aix-en-Provence.

OPPERMANN M., 1993, Tourism space in developing countries, Annal of Tourisme Research, 20, 3.

STACHOWSKI J., 1993, O pojmowaniu przestrzeni w geografil turystycznej, Acta Universitatis Nicolai Copernici. Geografia, 24.

SzkuP R., 2003, Ksztattowanie podmiejskiej przestrzeni wy poczynkowej. Przyktad zachodniego sektora strefy podmiejskiej Łodzi, Wyd. Uniwersytetu Łódzkiego, Łódż.

SzWichtenBerg A., 1998, Pojmowanie turystyki wiejskiej w Polsce i na świecie, Turyzm, 8/1.

WILUŚ R., 1997, Rozwój funkcji turystycznej w dolinie rzeki Warty na odcinku od Dziatoszyna do Uniejowa, ser. „Szlakami Nauki”, 24, Łódzkie Towarzystwo Naukowe, Łódż.

WhodARCZYK B., 1999, Przemiany form aktywności tury. stycznej na obszarze pótnocnej czéści krawędzi Wyży. ny Łódzkiej, ser. „Szlakami Nauki”, 29, Łódzkie Towarzystwo Naukowe, Łódź.

WOJCIECHOWSKA J., 1998, Kolonizacja turystyczna terenów nadpilicznych, ser. "Szlakami Nauki”, 26, Łódzkie Towarzystwo Naukowe, Łódż. 